\title{
Lipoma on the antitragus of the ear
}

\author{
Hyeree Kim, Sang Hyun Cho, Jeong Deuk Lee, Hei Sung Kim* \\ Department of Dermatology, Incheon St. Mary's Hospital, College of Medicine, The Catholic University of Korea, Seoul, Korea
}

Received: February 29, 2016; Accepted: March 25, 2016; Published: March 30, 2016

*Corresponding author: Hei Sung Kim, Professsor, Department of Dermatology, Incheon St. Mary's Hospital, College of Medicine, The Catholic University of Korea, 56 Donsuro, Bupyeong-gu, Incheon, 403-720, Korea. Tel: 82-32-280-5100; Fax: 82-2-506-9514; E-mail: hazelkimhoho@gmail.com

Keywords: Auricular Lipoma; Ear helix lipoma; Cartilagiouslipoma; Antitragallipoma

\section{Dear Editor,}

Lipomas are the most common soft-tissue neoplasm [1, 5]. Although they affect individuals of a wide age range, they occur predominantly in adults between the ages of 40 and 60 years [5]. They most commonly present as painless, slowly enlarging subcutaneous mass on the trunk, neck, or extremities. Involvement of the head, hands, and feet is uncommon [5]. To our knowledge, lipoma on the cartilaginous portion of the ear (auricular helix) has been reported only three cases so far $[1,6$, 7]. Herein, we report a rare case of lipoma on the antitragus of the ear.

A 31 year-old Korean woman presented with an asymptomatic, solitary, $0.5 \mathrm{~cm}$-sized, skin-colored, firm, immovable mass on the antitragus of the left ear for one year (Fig.1A). She denied of previous trauma, infection, sun exposure, and etc. We initially suspected the mass as a dermatofibroma or nevus, because of its clinical manifestation and performed a skin biopsy for confirmative diagnosis.

Histopathology revealed an unencapsulated intradermal lipoma composed of lobules of mature adipocytes separated by delicate fibrovascular septa (Fig.1B). A final diagnosis of dermal lipoma was made. We recommend complete excision, but the patient was lost for follow-up.

Lipomas are benign tumors made up of mature fat cells [4]. They can be solitary or multiple, small or big, symptomatic or asymptomatic. Lipomas are mostly asymptomatic but rarely accompany pain by pressing the adjacent structures. Apart from the fat cells, they may also contain fibrous tissue, nerves or vascular tissue. Such cases are named accordingly as fibrolipoma, neurolipoma, angiolipoma, etc [4]. Based on their location, they are also classified as dermal, subcutaneous, submucous or intramuscular lipomas $[4,5]$.

Approximately $15 \%$ of all lipomas occur in the head and neck area with the posterior neck being the most common site [1] They rarely involve the face, scalp, orbit, nasal cavity, paranasal sinuses, nasopharynx, cranium or ear [2]. When the lipomas are on the ear, most are located in internal auditory canals, where approximately 150 cases have been reported in the literature worldwide [3]. Lipomas rarely originate from the external ear where only a few cases have been reported from the ear lobule [4], and a only three cases from the ear helix [1,6,7] Bassem et al. reported a case of lipoma of the pinnal helix on the 82-year-old woman, which presented a single, $3 \times 3 \times 2 \mathrm{~cm}$-sized, pedunculated mass [1]. Mohammad and Ahmed reported two cases of cartiligious lipoma, one is conchal lipoma and the other is helical lipoma in 2015 [6, 7]. To our knowledge, only these three case of lipomas that have been on the cartilaginous part of the ear.

Lipomas from the cartilaginous part of the ear are very rare, but it is possible because of the presence of a thin adipose tissue layer on the auricle [1]. It should be considered as a differential diagnosis of benign tumors of auricle which usually includes papilloma, fibroma and chondromata and hemangioma etc [1].

Lipomas are removed mostly for cosmetic purposes. The treatment of choice is complete excision under local anesthesia [1-5]. Most lipomas are benign except liposarcoma. Local recurrence is rare except for the intramuscular forms. Metastasis does not occur [5].

So far, only three case of lipomas on the cartilaginous part of the ear has been reported, making this location very unusual for a lipoma $[1,6,7]$.

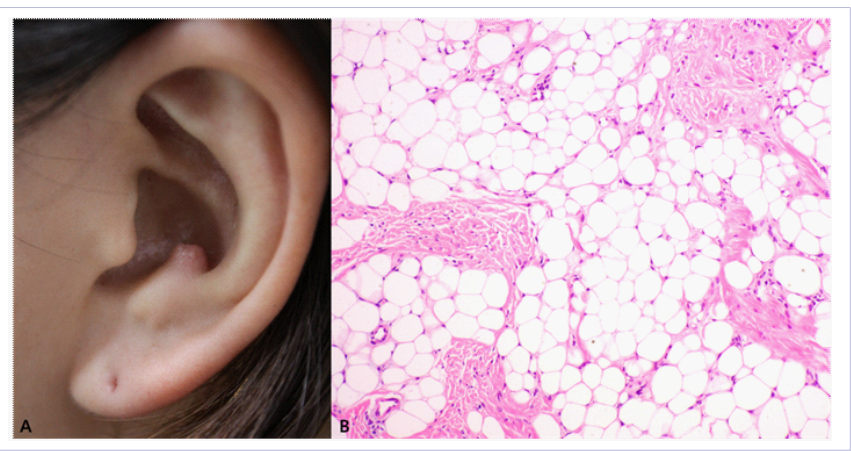

Figure 1: A: There is a $0.8 \mathrm{~cm}$-sized, skin-colored, firm mass on the antitragus of left ear for 1 year.

B: Histopathologic findings revealed mass is composed of lobules of mature white adipose tissue divided by delicate and inconspicuous fibrous septa containing thin-walled capillary-sized vessels.(H\&E, x100) 
We herein report a rare case of lipoma on the antitragus of the left ear.

\section{References}

1. Bassem M, Amir F, Aaron T, Bansal A, Zeitoun H. Lipoma of the pinnal helix : a very unusual location for a very common tumour. BMJ Case Reports. 2012;10:1136-1137. doi: 10.1136/bcr.12.2011.5339.

2. Barnes L. Tumors and Tumor-Like Lesions of the Soft Tissues. Surgical Pathology of the Head and Neck . 2nded. 2001;2:915-918.

3. Andrea B, Filippo DL, Elisa V, Pasanisi E, Russo A, Sanna M.Lipomas of the Internal Auditory Canal and Cerebellopontine Angle. Ann Otol Rhinol Laryngol. 2014;123(1):58-64. doi: 10.1177/0003489414521384
4. Nambi GI, Sachi K, Paul MK, Gupta AK. Lipoma-common tumour in an uncommon location. J Plast Reconstr Aesthet Surg. 2009;62(11):490491. doi: 10.1016/j.bjps.2008.08.046

5. Thomas B. Neoplasm of subcutaneous fat. Fitzpatrick's dermatology in general medicine. 8th ed. New-york; Mc-Graw-hill; 2012.p.1489-1491.

6. Mohammad EA, Ahmed S. Conchal lipoma: A new lipoma site. Inter Adv Otol. 2015;11(1):92-94. doi: 10.5152/iao.2015.738.

7. Ahmed HS, Mohammad EA. Helical lipoma in adult female. Indian J Otol. 2015;21(4):303-305. DOI: 10.4103/0971-7749.164547. 